\title{
Measurement of mercury in human urine
}

D. M. GOLDBERG AND A. D. CLARKE

From the Department of Chemical Pathology, The Royal Hospital, Sheffield

SYNOPSIS Four methods of determining the concentration of mercury in human urine have been studied. A simple method suitable for general laboratory use is recommended and the requirements for accurate results are defined. The method employs mild oxidation witlo permanganate and $\mathrm{HS}_{2} \mathrm{O}_{4}$ followed by dithizone extraction and measurement of absorbanceeo at $485 \mathrm{~nm}$ and $620 \mathrm{~nm}$.

No mercury was detected in any of 74 urines from unexposed laboratory controls and hos: pital patients. A random urine sample seems adequate for the investigation of clinical os industrial mercury poisoning. Two individuals, free of symptoms, but subjected to moderata exposure, excreted $3 \cdot 0-9 \cdot 7 \mu \mathrm{g}$ of mercury per $100 \mathrm{ml}$ of urine.

After the administration of an organic mercurial to two volunteers, urinary excretion was rapid and virtually complete within 48 hours.

The symptoms of mercury poisoning are vague and non-specific, and the clinical signs few (Buckell, Hunter, Milton, and Perry, 1946; Warkany and Hubbard, 1951). Considerable responsibility thus rests upon the laboratory, since the measurement of mercury in the urine offers virtually the only objective method of substantiating the diagnosis.

The techniques proposed for the measurement of mercury in biological materials include electrodeposition (Stock and Zimmerman, 1928), distillation (Kozelka, 1947), vapour detection (Monkman, Maffet, and Doherty, 1956), atomic absorption spectrophotometry (Lindstrom, 1959; Willis, 1962), and radio-activation analysis (Rodger and Smith, 1967). For the analysis of urine, oxidation of organic matter followed by dithizone extraction has been most popular, and earlier work in this field is described by Maren (1943), Gray (1952), Polley and Miller (1955), Rolfe, Russell, and,Wilkinson (1955), and Nobel and Nobel (1958). The published figures for 24hour urinary excretion of mercury in the normal subject show discrepancies, viz, 5-90 $\mu \mathrm{g}$ (Buckell et al, 1946), less than $1 \mu \mathrm{g}$ (Monier-Williams, Received for publication 1 January 1969.
1949), 0-50 $\mu \mathrm{g}$ (Warkany and Hubbard, 1951 융 less than $5 \mu \mathrm{g}$ (Tompsett and Smith, 1959), les\$ than $30 \mu \mathrm{g}$ (Nobel and Leifheit, 1961), and less than $20 \mu \mathrm{g}$ (Berman, 1967).

The object of this study was to establish the method most suitable for general laboratorif use and to define the requirements for accurate analytical results. We have confined ourselves to four variants of the dithizone technique sincer the apparatus required is inexpensive and the analysis is rapid.

\section{Materials and Methods}

The bottles used for urine collections and analy모 tical glassware were soaked in $50 \%(\mathrm{v} / \mathrm{v})$ nitri acid for 24 hours and thoroughly rinsed, firs 1 with water and then with a dilute solution of dith $\mathbb{B}$ zone immediately before use and rejected if ang colour change took place in the dithizone remaining in contact with the glass. All reagento were Analar grade or, where possible, 'low in. heavy metals'. Dithizone in high-grade crystalline form was obtained from Eastman Kodak. This 
proved satisfactory without further purification, as documented by Campbell and Head (1955), Miller and Swanberg (1957), Nobel and Nobel (1958), and Nobel and Leifheit (1961). Other dithizone preparations used in preliminary work not included in this report required purification as described by Milton and Hoskins (1947). Mercuric chloride, after thorough desiccation, served as standard. A brief outline of the methods used follows: adequate details are given in the original publications.

METHOD A (VARLEY, 1963)

Urine is refluxed with sulphuric acid and permanganate using gentle heat. Decolorization with hydroxylamine is followed by extraction into dithizone. It is stated that the dithizone extract may be treated in one of two ways: the absorbance at $490 \mathrm{~nm}$ and $620 \mathrm{~nm}$ may be determined without further treatment and the mercury content calculated according to the formula of Clarkson and Kench (1956); or it may be washed twice with $5 \%$ ammonia as recommended by Milton and Hoskins (1947) to remove free dithizone, after which the absorbance at $480 \mathrm{~nm}$ due to mercury dithizonate is measured. Since the absorbance of the dithizone reagent at $490 \mathrm{~nm}$ and $620 \mathrm{~nm}$ was 1.410 and 3.2 respectively using a $1-\mathrm{cm}$ light path, it is clearly inappropriate to carry out optical measurements on the untreated dithizone extract. We found that a minimum of four successive washes with $5 \%$ ammonia were required to remove excess of free dithizone from the extract, during which steps the organic layer became emulsified and required centrifugation before optical measurements could be made.

METHOD B (TOMPSETT AND SMITH, 1959) Urine is refluxed for two hours with a mixture of acids and selenium powder. Permanganate oxidation is then carried out, followed by hydroxylamine treatment. Mercury is extracted into dithizone, the absorption of which is read at $620 \mathrm{~nm}$. The dithizone extract is then treated with acid sodium thiosulphate to split mercury dithizonate and the absorption at $620 \mathrm{~nm}$ once more determined. The difference between the two readings is a measure of the mercury present. In theory, the second reading should be greater than or equal to the first reading. In practice this was not always so, and considerable uncertainty exists when measuring small quantities of mercury because of the need to subtract a large value from one only a little greater.

METHOD C (NOBEL AND LEIFHEIT, 1961) Urine is treated with sulphuric acid, copper sulphate, and hydrazine, followed by sodium hydroxide, sulphuric acid, capryl alcohol, and potassium permanganate; the latter is then

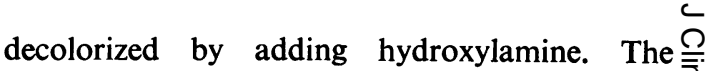
solution is then washed with chloroform, and extractive titration with dithizone is carried out. This involves the addition of $0.5 \mathrm{ml}$ portions of $\underline{ }$ dithizone in chloroform to the solution followed by shaking, and separation of the organic phase. Titration is complete when the blue-green colour of a portion of the dithizone does not change when added to the solution, shaken, and allowed $\frac{\bar{s}}{\frac{1}{2}}$ to separate. The volume of the dithizone solution $\propto$ required to achieve this is a measure of the mercury present.

METHOD D (WALL AND RHODES, 1966)

Since this method was finally adopted, it is described in detail incorporating modifications $\omega$ recommended by the present authors.

\section{Reagents}

1 Potassium permanganate

2 Sulphuric acid $50 \%(\mathrm{v} / \mathrm{v})$

3 Hydroxylamine hydrochloride $50 \%(\mathrm{w} / \mathrm{v})$

4 Carbon tetrachloride

5 Sodium sulphate (anhydrous)

6 Mercuric chloride (desiccated)

7 Diphenylthiocarbazone (Dithizone') dissolve about $1 \mathrm{mg}$ in approximately $10 \mathrm{ml}$ chloroform and add carbon tetrachloride (approximately $250 \mathrm{ml}$ ) to give an absorbance at $485 \mathrm{~nm}$ of $0.20 \stackrel{2}{\circ}$ to 0.25 when read against $\mathrm{CCl}_{4}$ in a $1-\mathrm{cm}$ light $\frac{\circ}{\Phi}$ path cuvette. Prepare freshly each day. Stopper and keep in the dark when not in use.

\section{Technique}

To a $250 \mathrm{ml}$ Erlenmeyer flask add successively $50 \mathrm{ml}$ urine, $3 \mathrm{~g} \mathrm{KMnO}_{4}$ (rough balance), and $10 \mathrm{ml}$ of $50 \% \mathrm{H}_{2} \mathrm{SO}_{4}$. Stand for five to 10 minutes 웅 to allow frothing to settle, cover the flask with a watch glass, and simmer on a hot plate set to give a temperature of the flask contents of $50^{\circ} \mathrm{C} \pm$ $2^{\circ} \mathrm{C}$.

After 30 minutes carefully add hydroxylamine, $D$ $0.5 \mathrm{ml}$ at a time, until decolorization is complete. When all solid matter is completely dissolved, $\stackrel{\sim}{\circ}$ add a further $0.5 \mathrm{ml}$ hydroxylamine. After cooling, add $10 \mathrm{ml}$ dithizone, stopper the flask, and shake ${ }^{\circ}$ vigorously for 30 seconds. Transfer to a separat- $\omega$ ing funnel and run off the organic layer quantitatively to a centrifuge tube.

Unless the green colour of the dithizone is unaltered, add a further $10 \mathrm{ml}$ to the aqueous ? phase, shake, and separate as before, repeating ${ }_{0}^{\circ}$ the process if necessary. One extraction should $\stackrel{\vec{\Phi}}{\vec{D}}$ suffice where the mercury content of the flask $\stackrel{\odot}{\oplus}$ is $5 \mu \mathrm{g}$ or less, and three extractions for a content $\stackrel{D}{2}$ of 15 to $20 \mu \mathrm{g}$. For very high levels, the totalo volume after the addition of hydroxylamine mayo be measured and extraction with dithizone응 carried out on a small portion. To each discrete dithizone extract add anhydrous sodium sul-

'Eastman Kodak catalogue no. 3092 
phate to absorb any water present and centrifuge at $500 \times g$ for two minutes. Read the absorbance at $485 \mathrm{~nm}$ and $620 \mathrm{~nm}$ using $\mathrm{CCl}_{4}$ as reference. When more than one extraction is required, it is convenient to pool the extracts from that sample, mix thoroughly, add sodium sulphate to an aliquot, and read after centrifugation.

A reagent blank in which water replaces urine, and two standards (5 $\mu \mathrm{g}$ and $10 \mu \mathrm{g}$ ) made up to $50 \mathrm{ml}$ in water, are processed with each batch of tests. The difference in absorbance at $485 \mathrm{~nm}$ between blank and test is compared with the corresponding difference between blank and standard to give the amount of mercury in the $50 \mathrm{ml}$ urine sample. When a pooled extract is measured, the difference in absorbance between test and blank is multiplied by the number of extractions to correct for dilution of the mercury dithizonate by $\mathrm{CCl}_{4}$. The absorbance at $620 \mathrm{~nm}$ serves to rule out oxidation of dithizone or the presence of other metals as outlined subsequently. Absorbance determinations at single wavelengths were made with the Uvispeck ${ }^{1}$ spectrophotometer and absorption curves were drawn with the SP 800 recording spectrophotometer ${ }^{2}$.

\section{Results}

\section{METHOD A}

When this method was applied according to the description of Varley (1963), the range of values obtained for daily mercury excretion in the urine of 13 unexposed laboratory personnel was $100-650 \mu \mathrm{g}$. The spectrum of the pure mercury standard bore little relationship to that of the urine extract (Fig. 1 presents a typical example of each) so that the absorbance of the latter ${ }^{1}$ Hilger and Watts, London

'Unicam Instruments, Cambridge, England

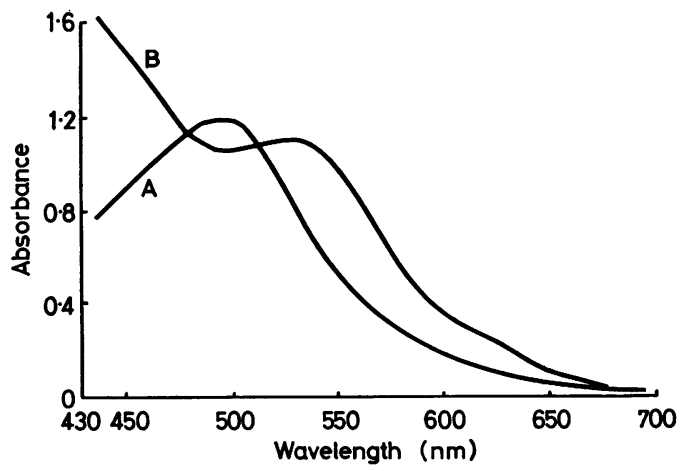

Fig. 1 Absorption curves of $10 \mu g$ mercury standard $(A)$ and a single urine containing $10 \mu g$ mercury per $50 \mathrm{ml}(B)$ obtained by the method of Varley (1963) after shaking dithizone extract with $4 \times 10 \mathrm{ml} 5 \%$ (v/v) ammonia. at $480 \mathrm{~nm}$ is not a measure of the mercur $\frac{\rho}{5}$ present.

\section{METHOD B}

Duplicate determinations of urines containin $1-19 \mu \mathrm{g}$ mercury per $100 \mathrm{ml}$ differed by as muct as $35 \%$. Poorer results were obtained befor we realized the decay in colour that took place in the dithizone extract before and after thioe sulphate reversion, even when held in the dark This decay averaged $1 \%$ per minute and was greatly accelerated by exposure to light. As it was desirable to centrifuge the organic phase befor reading on each occasion, some decay was in? evitable, and doubtless was the major facto 8 contributing to the imprecision of the method

\section{METHOD C}

We are in agreement with Nobel and Leifhei (1961) regarding the sensitivity of this method, although we find the technique of extractive titration a tedious procedure in comparison witis optical measurements. A more serious objection. lies in the accuracy of the technique which dee pends upon the addition of small aliquots of dithizone until the blue-green colour is unaltered It is not possible to distinguish adequately bes tween the colour of the mercury dithizonate an that of oxidized dithizone, as described subse quently, so that without spectral analysis on 8 cannot be certain that alteration of the blue green dithizone is exclusively due to mercury

\section{METHOD D}

This was the most rapid of the four method? and, with the modifications made, proved to be both accurate and precise. The following alteras tions did not affect the results obtained fron urines to which a known amount of mercury was added: varying the amount of $\mathrm{KMnO}_{4}$ from 3 to $6 \mathrm{~g}$, the volume of $\mathrm{H}_{2} \mathrm{SO}_{4}$ from 10 to $20 \mathrm{~m}$ the time of oxidation from 30 to 60 minutes, an $\overline{7}$. the volume of hydroxylamine added after com plete solubilization of the permanganate from 0.5 to $3.0 \mathrm{ml}$. Carrying out the oxidation stage at $100^{\circ} \mathrm{C}$ using a reflux condenser gave results identical with those obtained at $50^{\circ} \mathrm{C}$ in one set of experiments; in another set, the resulf at $100^{\circ} \mathrm{C}$ were lower by a mean of $12 \%$, possibl due to volatilization of the mercury.

The increase in absorbance at $485 \mathrm{~nm}$ bore linear relationship to mercury added when rea on single extracts (Fig. 2, line A) or on poolef extracts (Fig. 2, line D). Although we did no甲 routinely use standards higher than $20 \mu \mathrm{g}$ ir $50 \mathrm{ml}$, much higher concentrations were measuro able as in the urine of patients after mersalyp and we can see no reason why a linear relation. ship should not hold indefinitely provided the dithizone extractions are continued until the 


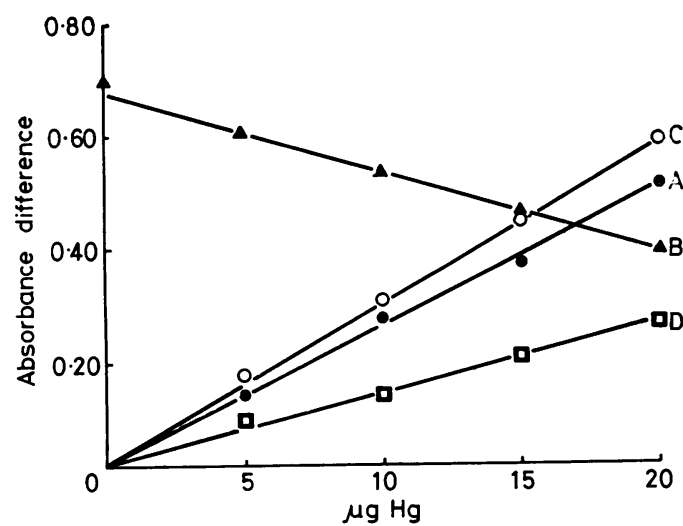

Fig. 2 Absorbance differences between reagent blank and $50 \mathrm{ml}$ water containing various amounts of mercury. Line A plots the sum of the differences at $485 \mathrm{~nm}$ between the blank and individual dithizone extracts ( $t$ wo extractions at each point).

Line $D$ plots the difference at $485 \mathrm{~nm}$

between the blank and the pooled dithizone extracts. Line $B$ plots the difference at $620 \mathrm{~nm}$ between the blank and the pooled dithizone extracts. Line $C$ plots the sum of differences at $485 \mathrm{~nm}$ and $620 \mathrm{~nm}$ between the blank and the pooled dithizone extracts.

original colour is no longer altered, and the organic material does not exceed the oxidative capacity of the $\mathrm{KMnO}_{4}$ and $\mathrm{H}_{2} \mathrm{SO}_{4}$. In connexion with this last point, the addition of 0.2 to $1.0 \mathrm{ml}$ of human plasma $(6.9 \mathrm{~g}$ protein $/ 100 \mathrm{ml})$ to urines containing mercury was without effect.

The absorption curves in Fig. 3 describe the changes occurring during formation of mercury dithizonate. The peak at $620 \mathrm{~nm}$ shown by dithizone is reduced by mercury with the simultaneous formation of a peak at $485 \mathrm{~nm}$. The spectrum of the reagent blank was identical with that of dithizone, and the spectrum of mercury dithizonate formed from aqueous standard was identical with that formed in the presence of urine, except for the qualifications to be described. The recovery of mercury standard from 20 urines averaged $98.8 \%$ with a SD of $\pm 2.9 \%$. When organic mercurial compounds were added to urines over the range 5-20 $\mu \mathrm{g}$ mercury per flask, the increase in $E_{485}$ was proportional to the amount added, and the recovery was satisfactory. These compounds were mercury orange in dichloroethane; mercury dibenzyl in acetone; mercury chloranilate in acetone; mercury diphenyl in ethanol; and $p$-chloromercuribenzoate in dilute $\mathrm{NaOH}$.

The reduction in absorbance at $620 \mathrm{~nm}$ was proportional to the amount of mercury present (Fig. 2, line B) and may be used as an index of mercury concentration. It is also possible to increase sensitivity by summing the absorbance differences between test or standard and blank at both $485 \mathrm{~nm}$ and $620 \mathrm{~nm}$. This gives a line more than twice as high as that based on measure-

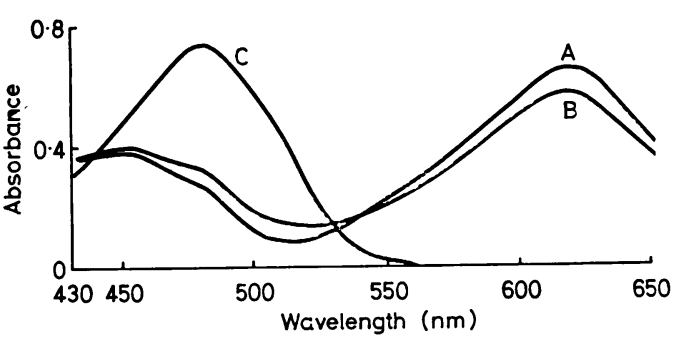

Fig. 3 Absorption curves of reagent blank $(A)$, dithizone saturated with mercury $(C)$, and urine containing $2 \mu \mathrm{g}$ mercury per $50 \mathrm{ml}(B)$ obtained by the method of Wall and Rhodes (1966).

ment at $485 \mathrm{~nm}$ alone (Fig. 2, line C). A number of problems, however, make the use of readings i at $620 \mathrm{~nm}$ unsatisfactory for analytical purposes. Whereas the absorbance at $485 \mathrm{~nm}$ was stable $\infty$ for up to 150 minutes when solutions were held 의 in stoppered tutes kept in the dark, the absorbance at $620 \mathrm{~nm}$ declined by about $15 \%$ over this period. In bright sunlight and in unstoppered tubes, the fall at $485 \mathrm{~nm}$ and $620 \mathrm{~nm}$ averaged $8 \%$ and $24 \%$ respectively over one hour, the decay being directly related to the intensity of sunlight and inversely related to the mercury concentration of the extract. The major source of instability is probably unaltered dithizone which has a value of 3 for the ratio $E_{620}: E_{485}$. Because at $620 \mathrm{~nm}$ a large value is subtracted from one a little larger, precision is poor. Twenty duplicate determinations over the range 1-20 $\mu \mathrm{g}$ mercury gave at $485 \mathrm{~nm}$ a mean percentage difference and SD of $3.9 \pm 1.9$; at $620 \mathrm{~nm}$ the corresponding values were $7 \cdot 0 \pm 2 \cdot 8$. Precision was much poorer when the absorbance differences at $485 \mathrm{~nm}$ and $620 \mathrm{~nm}$ between test and blank were summed.

The decrease in absorbance at $620 \mathrm{~nm}$ was not specific to mercury whereas the increase at $485 \mathrm{~nm}$ was. Addition to urine or to urine laced $\frac{}{2}$ with mercury of $\mathrm{Fe}^{++}, \mathrm{Cu}^{++}$, and $\mathrm{Zn}^{++}$in $\frac{\$}{2}$ quantities up to $1 \mathrm{mg}$, and of $\mathrm{Cd}^{++}$and $\mathrm{Pb}^{++}$ in quantities up to $50 \mu \mathrm{g}$ caused in some instances $N$ distortion of the spectrum of dithizone or of mercury dithizonate, usually associated with $\mathcal{N}^{-}$ reduction in absorbance at $620 \mathrm{~nm}$ but never with $\omega$ alteration in absorbance at $485 \mathrm{~nm}$.

Some urines caused a reduction in absorbance

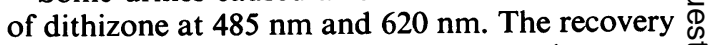
of $5 \mu \mathrm{g}$ mercury from four such urines was + $101 \%, 97 \%, 82 \%$, and $65 \%$ based on absorbance measurements at $485 \mathrm{~nm}$. This problem $\underset{\mathbb{D}}{\stackrel{D}{ }}$

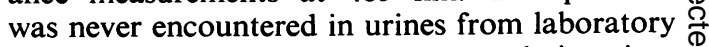
controls but occurred not uncommonly in urines $\varnothing$ from inpatients. Where it was important for $\bar{\sigma}$ diagnostic reasons to exclude mercury poisoning, 8 all drug therapy was stopped and within three days a satisfactory urine sample was obtained. The phenomenon appears to represent oxidation $\stackrel{\nexists}{\rightleftharpoons}$ 
of dithizone to diphenylthiocarbodiazone by inorganic ions in the urine or organic material surviving permanganate treatment (Barrett, 1956). Addition of excess $\mathrm{KMnO}_{4}$ and $\mathrm{H}_{2} \mathrm{SO}_{4}$ in the first stage did not prevent dithizone oxidation; nor did substitution of the wet oxidation techniques of methods A-C. On the other hand the addition of one tablet of aspirin, codeine, paracetamol, and ampicillin to $50 \mathrm{ml}$ normal urine decreased the absorbance of the dithizone extract at $620 \mathrm{~nm}$ without decreasing it at $485 \mathrm{~nm}$. Such drugs were among the commonest taken by patients producing urines capable of oxidizing dithizone.

STUDIES ON HUMAN SUBJECTS

Twenty-four healthy laboratory staff, including those whose urines had previously been analysed by method $\mathrm{A}$, had no detectable mercury in 50 $\mathrm{ml}$ of urine when analysed by method $\mathrm{D}$. The limit of detection was regarded as $0.5 \mu \mathrm{g}$ mercury, corresponding to an absorbance difference between test and blank of +0.015 at $485 \mathrm{~nm}$ and -0.015 at $620 \mathrm{~nm}$. None of these urines caused oxidation of dithizone and each was part of a 24-hour collection. Future tests were carried out on an overnight sample, positive results being followed by analysis of a 24-hour specimen.

Urines of 50 inpatients not suspected of exposure to mercury gave negative results. In eight, the first sample caused oxidation of dithizone. Eighteen samples from patients in whom the question of mercury toxicity arose were analysed. One positive result was obtained. This was in an industrial worker aware of a ventilation fault in a room where he carried out processes involving use of a mercury still. He was completely symptom-free but desired a check-up. At two, four, five, and six days after termination of exposure, his daily excretion was $149,64,45$, and $54 \mu \mathrm{g}$ mercury. None of the remaining patients examined (mostly infants) had a history of exposure to mercury, and the analysis was requested towards the end of investigations when more likely possibilities had been excluded.

Urines from 103 industrial workers were examined. Fifteen engaged in work which occasionally involved the use of mercury; the remainder were divided almost equally into those working with metals other than mercury, and those who in the course of their work did not normally come into contact with metals. The laboratory was unaware of the status of the subjects before analysis. Mercury in a concentration of $7 \mu \mathrm{g} / 100 \mathrm{ml}$ was found in the urine of one symptomless subject in the group exposed to mercury. No other positive results were obtained, but eight of the urines from those exposed to metals other than mercury caused oxidation of dithizone. It was subsequently discovered that five of the eight had been taking aspirin, codeine, or paracetamol the night before the sample was taken; the other three could not be traced at the time of follow up.

One $\mathrm{ml}$ of mersalyl BP (39.7 $\mathrm{mg}$ mercuryp was given by intramuscular injection to tw volunteers. Urine from the first volunteer was collected 12-hourly for three days. During the time, $36.2 \mathrm{mg}$ of mercury was excreted in the urine, $98.9 \%$ of this being passed in the first 12-hour sample. By the third day, the totaly 24-hour excretion was only $32 \mu \mathrm{g}$. Urine from the second volunteer was collected six hourly fof 48 hours. During this time $34.1 \mathrm{mg}$ of mercury was excreted, $77.9 \%$ of this being passed in the first six-hour sample and $14.8 \%$ in the second. The last six-hour sample contained only $9 \cdot 2 \mu \overrightarrow{\mathrm{sg}}$ mercury.

\section{Discussion}

The method of Varley (1963) proved to be highß inaccurate and that of Tompsett and Smith (1959) imprecise. Thiosulphate reduces mercuky recovery (Campbell and Head, 1955) and its use may contribute to the imprecision of the method of Tompsett and Smith (1959). We noted the instability of the extract in this method, and and have learned that the sequence of extractioce first reading, reversion, and second reading shou be completed without delay on each digest individually (Tompsett, personal communic星 tion). This raises problems in batch analysi\& The sensitivity of the method is less than the्ध of the Wall and Rhodes technique when extract are read individually: $20 \mu \mathrm{g}$ mercury gave a absorbance difference in a $1-\mathrm{cm}$ light path $\overline{F f}$ 0.200 at $620 \mathrm{~nm}$ by the method of Tompsett an Smith (1959) and 0.565 at $485 \mathrm{~nm}$ by the methog of Wall and Rhodes (1966).

The method of Nobel and Leifheit (1961) tedious, and extractive titration may give mis. leading results due to alteration of dithizone by factors other than mercury. The method of Wall and Rhodes (1966) is simple and rapid at employs few reagents, thereby minimizing the risk of contamination and high reagent blanks Two further problems in the estimation of meno cury lie in the volatility of the metal and ins compounds, and the necessity of ensuring the correct $p \mathrm{H}$ during extraction with dithizonte. With regard to the first point, no mercury wos lost when the duration of wet oxidation w\$s twice the recommended period, and good recovery of mercury was obtained when inorganic and organic mercurials were added to urine. Wi regard to the second point, the $p \mathrm{H}$ of the solge tion before the addition of the dithizone alwa ss lay within the range -1 to 0.6 as recommended by Irving, Andrew, and Risdon (1949) and it wass considered unnecessary to check this routine. The modifications proposed, apart from more rigorous standardization of the technique, inclu $\overline{\bar{p}}$ 
the addition of anhydrous sodium sulphate as used by Milton and Hoskins (1947) followed by centrifugation to remove traces of moisture from the organic phase; pooling of multiple extracts from positive samples instead of reading them individually, a procedure validated by Campbell and Head (1955); reading against $\mathrm{CCl}_{4}$ instead of against dithizone, and at $620 \mathrm{~nm}$ as well as at $485 \mathrm{~nm}$. These last modifications were essential in order to guard against changes in dithizone during a working day, although it was always freshly made and held in the dark, and to detect oxidation of dithizone by individual urine samples.

We have been unable to find an explanation for this phenomenon, or to confirm our suspicions that it may be related to drug metabolites, since administration of aspirin, codeine, paracetamol, and barbiturates to healthy controls did not lead to the production of such urines. Since chloride ions have been reported to decrease recovery of mercury (Kozelka, 1947; Campbell and Head, 1955) we substituted hydroxylamine sulphate for hydroxylamine chloride, without improvement; nor could we demonstrate a raised chloride content in such urines. Other wet oxidation techniques gave no better results. Miller and Swanberg (1957) have drawn attention to the similarity in colour between mercury dithizonate and diphenylthiocarbodiazone, the oxidation product of dithizone; they were unable to prevent formation of the latter in certain urines by the addition of a large number of reducing agents. Fats and fatty acids can survive most of the digestion techniques used in the preparation of organic materials for mercury analysis and are able to oxidize dithizone and the related compound di-beta-naphthylthiocarbazone (Cholak and Hubbard, 1946). It is thus apparent that previous workers have encountered problems due to oxidation of dithizone by urine and other biological materials, and that no solution has yet emerged. It is probable, moreover, that other workers have met the problem without recognizing it. This hazard is especially great with methods utilizing absorbance measurements at $620 \mathrm{~nm}$, since reduction in absorbance due to oxidation could be mistakenly attributed to mercury. This error is unlikely when absorbance at $485 \mathrm{~nm}$ is also determined. Fortunately, the problem does not often arise, and satisfactory urines were obtained from these patients after stopping all drugs, although this is not proof that drugs were related to the phenomenon in the first instance.

Our work supports the validity of a random urine sample for the diagnosis of mercury poisoning (Nobel and Leifheit, 1961); this was usually the first sample passed on waking. We are also in agreement with previous workers who have been unable to detect mercury in the urine of normal human subjects (Kozelka, 1947; Monier-Williams, 1949; Monkman et al,
1956; Tompsett and Smith, 1959). The recovery of mercury injected in the form of mersalyl from the urine of two subjects exceeded $90 \%$ of the administered dose. This provides further validation of the method, since no allowance was made for excretion via the skin, salivary gland and intestine, or possible retention in bone. The finding that half the dose administered appears in the urine within a few hours and most of the remainder within 24 hours agrees with the reports of earlier workers (Burch, Ray, Threefoot, Kelly, and Svedberg, 1950; Grossman, Weston, Lehman, Halperin, Ullmann, and Leiter, 1951).

We wish to thank Mr J. A. Adam, Dr B. P. R. Hartley, Dr J. D. Hobson, and Dr R. A. Trevethick who provided the urines from industrial workers, and Dr C. P. Stewart who kindly reviewed this manuscript. We are especially indebted to Dr Arthur Jordan for his criticism and encouragement throughout this investigation.

\section{References}

Barrett, F. R. (1956). Micro-determination of mercury in biological materials. Analyst, 81, 294-298.

Berman, E. (1967). Determination of cadmium, thallium and mercury in biological materials by atomic absorption. PerkinElmer Atom. Absorp. Newsl. 6, 57-60.

Buckell, M., Hunter, D., Milton, R., and Perry, K. M. A. (1946). Chronic mercury poisoning, Brit. J. industr. Med., 3. 55-63.

Burch, G., Ray, T., Threefoot, S., Kelly, F. J., and Svedberg, A. (1950). The urinary excretion and biologic decay periods of radiomercury labelling a mercurial diuretic in normal and diseased man. J. clin. Invest., 29, 1131-1138.

Campbell, E. E., and Head, B. M. (1955). The determination of mercury in urine-single extraction method. Industr. Hyg. Quart., 16, 275-279.

Cholak, J., and Hubbard, D. M. (1946). Microdetermination of mercury in biological material. Ind. Eng. Chem. Anal. Ed., $18,149-151$.

Clarkson, T. W., and Kench, J. E. (1956). Urinary excretion of amino acids by men absorbing heavy metals. Biochem. J., 62, 361-372.

Gray, D. J. S. (1952). The determination of traces of mercury in urine by the reversion technique. Analyst, 77, 436-438.

Grossman, J., Weston, R. E., Lehman, R. A., Halperin, J. P., Ullmann, T. D., and Leiter, L. (1951). Urinary and fecal excretion of mercury in man following administration of mercurial diuretics. J. clin. Invest., 30, 1208-1227.

Irving, H., Andrew, G., and Risdon, E. J. (1949). Studies with dithizone. Part I. The determination of traces of mercury. J. chem. Soc., pp. 541-547.

Kozelka, F. L. (1947). Determination of mercury in biological material. Anal. Chem., 19, 494-496.

Lindstrom, O. (1959). Rapid microdetermination of mercury by spectrophotometric flame combustion. Anal. Chem., 31, 461-467.

Maren, T. A. (1943). A simple and accurate method for the determination of mercury in biological material. J. Lab. clin. Med., 28, 1511-1514.

Miller, V. L., and Swanberg, F. (1957). Determination of mercury in urine. Anal. Chem., 29, 391-393.

Milton, R. F., and Hoskins, J. L. (1947). The estimation of traces of mercury in urine. Analyst, 72, 6-10.

Monier-Williams, G. W. (1949). Trace Elements in Food, p. 453. Chapman and Hall, London.

Monkman, J. L., Maffett, P. A., and Doherty, T. F. (1965). The determination of mercury in air samples and biological materials. Industr. Hyg. Quart., 17, 418-420.

Nobel, S., and Leifheit, H. C. (1961). In Standard Methods of Clinical Chemistry, edited by D. Seligson, vol. 3, p. 176. Academic Press, New York.

Nobel, S., and Nobel, D. (1958). Determination of mercury in urine. Clin. Chem., 4, 150-158. 
Polley, D., and Miller, V. L. (1955). Rapid microprocedure for determination of mercury in biological and mineral materials. Anal. Chem., 27, 1162-1164.

Rodger, W. J., and Smith, H. (1967). Mercury absorption by fingerprint officers using 'grey powder'. J. forens. Sci. Soc., 7, 86-89.

Rolfe, A. C., Russell, F. R., and Wilkinson, N. T. (1955). The absorptiometric determination of mercury in urine. Analyst, 80, 523-530.

Stock, J., and Zimmerman, W. (1928). Z. angew. Bäder-u Klimaheilk. Chem., 41, 546, cited by Milton, R. F., and Hoskins, J. L. (1947). (See above).

Tompsett, S. L., and Smith, D. C. (1959). Mercury in biological materials. J. clin. Path., 12, 219-221.

Varley, H. (1963). Practical Clinical Biochemistry, 3rd edn, p. 642. Heinemann, London.

Wall, H., and Rhodes, C. (1966). The effect of bacterial contamination and ageing on the volatility of mercury in urine specimens. Clin. Chem., 12, 837-843.

Warkany, J., and Hubbard. D. M. (1951). Adverse mercurial reactions in the form of acrodynia and related conditions. Amer. J. Dis. Child., 81, 335-373.

Willis, J. B. (1962). Determination of lead and other heavy metals in urine by atomic absorption spectroscopy. Anal. Chem., 34, 614-617.

\section{The February 1970 Issue}

\section{THE FEBRUARY 1970 ISSUE CONTAINS THE FOLLOWING PAPERS}

Mechanisms in intestinal transfer D. H. SMYTH

Pathological changes in virus infections of the lower respiratory tract in children W. AHERNE, T. BIRD, S. D. M. COURT, P. S. GARDNER, and JOYCE MCQUILLIN

Stability of neomycin resistance in Staphylococcus aureus G. A. J. AYLIFFE

Generalized herpes simplex in malnourished children A. C. TEMPLETON

Addendum A. H. TOMLINSON

The biological false positive reaction to serological tests for syphilis M. F. GARNER

The investigation of myelomatosis by gel isoelectric focusing followed by electrophoresis G. DALE, A. L. LATNER, and T. J. MUCKLE

The Australia antigen in Brazilian healthy persons and in leprosy and leukaemia patients F. M. SALZANO and B. S. BLUMBERG

Evaluation of a rapid method for the determination of plasma fibrinogen H. B. C. BURMESTER, K. AULTON, and G. I. HORSFIELD

An automated method for the measurement of folate activity R. E. DAVIS, D. J. NICOL, and A. KELLY

Automation of the assay of folate in serum and whole blood L. MILLBANK, R. E. DAVIS, MARY RAWLINS, and A. H. WATERS
An evaluation of the Fisher Hem-Alyzer T. R. J. LAPPIN, A. LAMONT, and M. G. NELSON

An artificial leucocyte control suspension T. R. J. LAPPIN and FRANCES M. SANDERSON

An assessment of the Coulter counter model S P. H. PINKERTON, I. SPENCE, J. C. OGILVIE, W. A. RONALD, PATRICIA MARCHANT, and P. K. RAY

A data processing system for hospital bacteriology M. K. ALEXANDER, J. CONNIGALE, T. JOHNSON, I. R. POULTER, and J. WAKEFIELD

A study of some of the methods of urinary collectiof in children NANCY K. CONN

An assessment of the Azostix strip test A. M. BOLD, I. S. MENZIES, and G. WALKER

\section{Technical methods}

A simple, safe nitroprusside test using Ketostix reagent strips for detecting cystine and homocystine in urine J. E. MIDDLETON

Direct microscopical examination of tube cultures for the detection of trichomonads G. I. BARROW and C. ELLIS

\section{Letters to the Editor}

Book reviews

Copies are still available and may be obtained from the PUBLISHING MANAGER, BRITISH MEDICAL ASSOCIATION, TAVISTOCK SQUARE, W.C.1 price 21 . 